\title{
Gallic Acid Hindered Lung Cancer Progression by Inducing Cell Cycle Arrest and Apoptosis in A549 Lung Cancer Cells via PI3K/Akt Pathway
}

\author{
Eul-Bee Ko, Yin-Gi Jang, Cho-Won Kim, Ryeo-Eun Go, Hong Kyu Lee and Kyung-Chul Choi* \\ Laboratory of Biochemistry and Immunology, College of Veterinary Medicine, Chungbuk National University, Cheongju 28644, \\ Republic of Korea
}

\begin{abstract}
This study elucidates the anti-cancer potential of gallic acid (GA) as a promising therapeutic agent that exerts its effect by regulating the PI3K/Akt pathway. To prove our research rationale, we used diverse experimental methods such as cell viability assay, colony formation assay, tumor spheroid formation assay, cell cycle analysis, TUNEL assay, Western blot analysis, xenograft mouse model and histological analysis. Treatment with GA inhibited cell proliferation in dose-dependent manner as measured by cell viability assay at $48 \mathrm{~h}$. GA and cisplatin (CDDP) also inhibited colony formation and tumor spheroid formation. In addition, GA and CDDP induced apoptosis, as determined by the distribution of early and late apoptotic cells and DNA fragmentation. Western blot analysis revealed that inhibition of the PI3K/Akt pathway induced upregulation of p53 (tumor suppressor protein), which in turn regulated cell cycle related proteins such as p21, p27, Cyclin D1 and E1, and intrinsic apoptotic proteins such as Bax, Bcl-2 and cleaved caspase-3. The anti-cancer effect of GA was further confirmed in an in vivo mouse model. Intraperitoneal injection with GA for 4 weeks in an A549-derived tumor xenograft model reduced the size of tumor mass. Injection of them downregulated the expression of proliferating cell nuclear antigen and p-Akt, but upregulated the expression of cleaved caspase-3 in tumor tissues. Taken together, these results indicated that GA hindered lung cancer progression by inducing cell cycle arrest and apoptosis, suggesting that GA would be a potential therapeutic agent against non-small cell lung cancer.
\end{abstract}

Key Words: Lung cancer, Gallic acid, Cell cycle, Apoptosis, PI3K/Akt

\section{INTRODUCTION}

Lung cancer is the leading cause of cancer-related deaths in the world, comprising small cell lung carcinoma and nonsmall cell lung carcinoma (NSCLC) which accounts for approximately $85 \%$ of lung cancer (Han and Roman, 2010) NSCLC is caused by smoking, secondhand smoke, radon, other toxic substances, and family history (Gridelli et al., 2015). Although NSCLC patients in the early stage can expect a complete recovery with surgery, about half of them relapse and it is even difficult to diagnose early. In fact, since more than half the people diagnosed as NSCLC with lung cancer die within one year of diagnosis, the five-year survival rates are quite low (Siegel et al., 2019). In practice, most patients undergo surgery combined with chemotherapy, resulting in experiencing several adverse effects such as chemoresistance accompanied with recurrence and even damage to normal cells (Zappa and Mousa, 2016).

Cisplatin (cis-diamminedichloroplatinum (II), CDDP) is the most common chemotherapeutic drug for different neoplasms, including lung, ovarian, breast and testicular cancers (Loehrer and Einhorn, 1984; Markman et al., 1991; Decatris et al., 2004; Pignon et al., 2008). CDDP induces DNA damage in cancer cells, thereby triggering cell cycle arrest and resulting in apoptotic cell death, via several molecular mechanisms such as mitogen-activated protein kinase (MAPK) and phosphoinositide 3-kinase (PI3K)/Akt pathways (Wang et al., 2000; Jones et al., 2007; Dasari and Tchounwou, 2014; Zhou et al., 2019). CDDP exerts a broad spectrum of anti-tumor activity. Because treatment of CDDP is often accompanied with side effects including nausea, vomiting, viscera toxicity, and tumor resistance (Yousef et al., 2009; Florea and Busselberg, 2011), it is necessary to identify more effective agents and fewer side effects. Over the past few decades, a number of

\section{Open Access https://doi.org/10.4062/biomolther.2021.074}

This is an Open Access article distributed under the terms of the Creative Commons Attribution Non-Commercial License (http://creativecommons.org/licenses/by-nc/4.0/) which permits unrestricted non-commercial use, distribution, and reproduction in any medium, provided the original work is properly cited.
Received Apr 19, 2021 Revised Jun 16, 2021 Accepted Jun 30, 2021 Published Online Jul 15, 2021

\section{*Corresponding Author}

E-mail: kchoi@cbu.ac.kr Tel: +82-43-261-3664, Fax: +82-43-267-3150 
<smiles>O=C(O)c1cc(O)c(O)c(O)c1</smiles>

Fig. 1. Chemical structure of gallic acid (GA).

natural compounds have been discovered that are now widely used as anti-cancer agents, including paclitaxel, vinblastine, camptothecin and oleuropein (Mou et al., 2011; Antognelli et al., 2019).

Gallic acid (3,4,5-trihydroxybenzoic acid, GA) (Fig. 1) is a naturally occurring polyphenol phytochemical found in nuts, teas and grapes (Badhani et al., 2015). GA has a wide range of bioactive functions that are beneficial to the human body, and encompass anti-oxidant, anti-inflammatory, anti-bacterial, anti-viral and anti-cancer activities (Choubey et al., 2015). Previous studies revealed that GA is more effective against tumor cells than against non-tumor cells (Inoue et al., 1994). Both in vitro and in vivo assays have confirmed the anti-cancer potential of GA against several tumor cell lines, including leukemia, melanoma, lung cancer and breast cancer (Lo et al., 2010; You et al., 2011; Wang et al., 2014; Sourani et al., 2016). Most studies about GA indicate that the anti-cancer activities related to the induction of apoptosis by different mechanisms, depending on the cell types (Locatelli et al., 2013). GA induces apoptosis via the regulation of MAPK pathways in human osteosarcoma cells (Liang et al., 2012), and via ROS-dependent mitochondrial apoptosis in human small cell lung cancer cells (Wang et al., 2016). These findings are sufficient to suggest that GA has promising therapeutic potentials for various cancer treatments.

The PI3K/Akt pathway plays a critical role in regulating diverse normal cellular processes. PI3K is activated by various extracellular stimuli such as growth factors, cytokines and hormones, via receptor tyrosine kinase. PI3K can also be activated by Ras, which is regulated by G-protein coupled receptors. Upon activation, PI3K stimulates the conversion of membrane-bound phosphatidylinositol-(4,5)-bisphosphate to phosphatidylinositol-(3,4,5)-triphosphate $\left(\mathrm{PIP}_{3}\right)$ as a secondary messenger. $\mathrm{PIP}_{3}$ recruits phosphatidylinositol-dependent kinase-1 (PDK1) to the cell membrane through its pleckstrinhomology domain. PDK1 then phosphorylates and activates the serine/threonine kinase Akt at threonine 308 (Thr308) (Yu and Cui, 2016). The mammalian target of rapamycin complex 2 attributes to the complete activation of Akt by phosphorylation at serine 473 (Ser473). This fully activated Akt phosphorylates downstream target proteins to promote cell proliferation, differentiation, survival, metabolism and metastasis (Chang et al., 2003). Aberrant activation of PI3K/Akt pathway is commonly observed in various cancers. The PI3K/Akt pathway is also activated in a large proportion of NSCLC, and is associated with poor prognosis (Cheng et al., 2014).

The object of this study was to confirm the anti-cancer effects and possible molecular mechanisms of GA compared with CDDP in NSCLC cells and tumor xenograft mouse model. These findings suggest the potential of GA as a PI3K/Akt pathway targeted therapeutic agent for NSCLC treatment.

\section{MATERIALS AND METHODS}

\section{Reagents and chemicals}

CDDP and GA (Fig. 1) were purchased from Sigma-Aldrich (St. Louis, MO, USA). CDDP was dissolved in sterile phosphate-buffered saline (PBS), and GA was dissolved in dimethyl sulfoxide (DMSO) used as a negative control (NC) or vehicle. The final concentrations of sterile PBS and DMSO were $1.5 \%$ and $0.1 \%$, respectively.

\section{Cell culture and media}

The NSCLC cell line A549, and normal human diploid lung fibroblast cell line WI-26, were purchased from the Korean Cell Line Bank (Seoul, Korea). A549 cells were cultured in RPMI-1640 (Gibco, Gaithersburg, MD, USA) supplemented with $10 \%$ fetal bovine serum (FBS; RMBIO, Missoula, MT, USA) and 2\% Antibiotic- Antimycotic (Gibco), and WI-26 cells were cultured in DMEM (HyClone Laboratories, Chicago, IL, USA) supplemented with $10 \%$ FBS (RMBIO), $100 \mathrm{U} / \mathrm{mL}$ penicillin $\mathrm{G} / 100 \mu \mathrm{g} / \mathrm{mL}$ (Biowest, San Marcos, TX, USA) and $1 \%$ HEPES (Gibco); Both cell lines were maintained at $37^{\circ} \mathrm{C}$ in a humidified atmosphere of $5 \% \mathrm{CO}_{2}$.

\section{Cell viability assay}

A549 and WI-26 cells were seeded at a density of $5 \times 10^{3}$ cells per well in 96-well culture plates, and incubated for $24 \mathrm{~h}$. Cells were then exposed to varying concentrations of CDDP (0-50 $\mu \mathrm{M})$ and GA (0-200 $\mu \mathrm{M})$, and incubated for $48 \mathrm{~h}$. Cell viability was determined using the EZ-Cytox cell viability assay kit (iTSBiO, Seoul, Korea). Briefly, the medium was removed and EZ-Cytox was added to all wells, incubated for $1 \mathrm{~h}$, with subsequent measurement of absorbance of each well at 450 $\mathrm{nm}$ using a microplate spectrophotometer (Epoch, BioTek, Winnoski, VT, USA).

\section{Colony formation assay}

A549 cells were seeded at a density of 500 cells per well in 6-well plates, and incubated for $24 \mathrm{~h}$, followed by exposure to NC $(0.1 \%$ DMSO), CDDP $(12 \mu \mathrm{M})$ and GA $(75 \mu \mathrm{M})$ and incubation for 10 days. The medium containing the appropriate chemical was replaced every 3 days. After 10 days, the cells were washed with Dulbecco's phosphate-buffered saline (DPBS; Welgene, Daegu, Korea), fixed with $4 \%$ formaldehyde (Sigma-Aldrich) for $10 \mathrm{~min}$, and permeabilized with methanol (Sigma-Aldrich) for $10 \mathrm{~min}$. The colonies formed by single cells were subsequently stained with $0.5 \%$ crystal violet solution and washed with DPBS. The stained colonies were counted by the Image $\mathrm{J}$ program (National Institutes of Health, Bethesda, MD, USA).

\section{Tumor spheroid formation assay}

A549 cells in medium containing NC ( $0.1 \%$ DMSO), CDDP $(12 \mu \mathrm{M})$ and GA $(75 \mu \mathrm{M})$ were seeded at 500 cells/25 $\mu \mathrm{L} /$ droplet on the lid of petri dish using an 8-channel pipette, and incubated for 6 days. After 6 days, each droplet was gently collected with medium and transferred to 6-well plates, and photographed using the IX-73 inverted microscope (Olympus, Tokyo, Japan). The size of tumor spheroids was measured by the Image J program (National Institutes of Health).

\section{Annexin $V$ assay}

The Annexin V assay was performed using Alexa Fluor 488 
or FITC Annexin V/Dead Cell Apoptosis kit (Invitrogen, Carlsbad, CA, USA). Briefly, A549 cells were seeded in cell culture dishes at a density of $8 \times 10^{4}$ cells, incubated for $24 \mathrm{~h}$, and subsequently treated with NC (0.1\% DMSO), CDDP $(12 \mu \mathrm{M})$ and GA $(75 \mu \mathrm{M})$ for $48 \mathrm{~h}$. The cells were then detached with trypsin and centrifuged at 2,000 rpm for $3 \mathrm{~min}$. The collected cells were suspended in $1 \mathrm{X}$ annexin-binding buffer and stained with Alexa Fluor 488 or FITC and PI for $15 \mathrm{~min}$ at room temperature in the dark. A total of $3 \times 10^{4}$ stained cells were analyzed by flow cytometry (SH800 Cell sorter, Sony, Tokyo, Japan).

\section{Terminal deoxynucleotidyl transferase (TdT)-mediated dUTP nick-end labeling (TUNEL) assay}

TUNEL assay was performed using the DeadEndTM Fluorometric TUNEL System (Promega, Madison, WI, USA), according to the instructions described in the kit. Briefly, A549 cells were seeded at a density of $3 \times 10^{4}$ cells per well in 24well plates and incubated for $24 \mathrm{~h}$. After treatment with $\mathrm{NC}$ (0.1\% DMSO), CDDP $(12 \mu \mathrm{M})$ and GA $(75 \mu \mathrm{M})$ for $48 \mathrm{~h}$, the cells were fixed with $4 \%$ paraformaldehyde (Biosesang Inc., Gyeonggi, Korea) for 25 min at $4^{\circ} \mathrm{C}$, followed by two washes with DPBS. Cells were permeabilized by adding $0.1 \%$ Triton X-100 for $10 \mathrm{~min}$, and subsequently washed with DPBS. Permeabilized cells were then stained with TUNEL mix solution, and the nuclei were counterstained with 4',6-diamidino-2-phenylindole (DAPI; Invitrogen). DNA fragmentation by CDDP or GA was visualized using the IX-73 inverted microscope (Olympus) and quantified using the Image $\mathrm{J}$ program (National Institutes of Health).

\section{Western blot assay}

After treatment of A549 cells with NC (0.1\% DMSO), CDDP $(12 \mu \mathrm{M})$ and $\mathrm{GA}(75 \mu \mathrm{M})$ for $48 \mathrm{~h}$, the total proteins were extracted using the EzRIPA Lysis Kit (ATTO, Tokyo, Japan) and quantified by bicinchoninic acid (BCA; Sigma-Aldrich), mixed with a copper II sulfate solution (Sigma-Aldrich) at a ratio of $50: 1$. Total cell proteins $(50 \mu \mathrm{g})$ were separated in $10 \%$ or $15 \%$ SDS-PAGE gel and transferred to a polyvinylidene difluoride (PVDF) membrane (Bio-Rad, Hercules, CA, USA). The transferred membrane was then blocked by $5 \%$ skim milk (Blotting-Grade Blocker; Bio-Rad) for an hour at $4^{\circ} \mathrm{C}$ on a shaker. The blocked membrane was then incubated overnight at $4^{\circ} \mathrm{C}$ on a shaker, with $5 \%$ bovine serum albumin (BSA, RMBIO) containing following primary antibodies: mouse monoclonal anti-GAPDH (1:10,000; Abcam, Cambridge, UK), mouse monoclonal anti-Cyclin D1 (1:2,000; Abcam), rabbit monoclonal anti-p27 (1:2,000; Abcam or 1:1000; Santa Cruz Biotechnology, Dallas, TX, USA), mouse monoclonal anti-Cyclin E1 (1:1,000; Santa Cruz Biotechnology), mouse monoclonal anti-p53 (1:1,000; Santa Cruz Biotechnology), mouse monoclonal anti-Bax (1:1,000; Online, Atlanta, GA, USA), mouse monoclonal anti-Bcl-2 (1:500; Bio Legend, San Diego, CA, USA), rabbit polyclonal anti-cleaved caspase-3 (1:2,000; Cell Signaling Technology, Danvers, MA, USA), rabbit monoclonal anti-p-Akt (Ser473, 1:2,000; Cell Signaling Technology), rabbit polyclonal anti-p-Akt (Thr308, 1:1,000; Bioss, Woburn, MA, USA), rabbit polyclonal anti-Akt (1:1,000; Bioss), and rabbit polyclonal anti-PI3K (1:300; Bioss). Primary antibody binding was detected by combining with secondary antibodies with horse radish peroxidase-conjugated anti-mouse IgG or antirabbit IgG (1:2,000; Thermo Scientific, Waltham, MA, USA) for $2 \mathrm{~h}$ at $4^{\circ} \mathrm{C}$ on shaker. Finally, the signals indicating expres- sion levels of target proteins were detected by applying the SuperSignal ${ }^{\mathrm{TM}}$ West Pico PLUS Chemiluminescent Substrate (Thermo Scientific) and Lumino graph II (ATTO). All protein expression levels were normalized and quantified using CSAnalyzer4 (ATTO).

\section{A549 cells derived tumor xenograft mice model}

BALB/c nude mice (males, 4 weeks old) were purchased from Orient Bio (Gyeonggi, Korea). The animal experiment was approved by the Animal Care Committee of Chungbuk National University (Cheongju, Korea) (CBNUA-1284-19-01). The mice were housed in the CBNU Laboratory Animal Research Center at $24^{\circ} \mathrm{C}$ under a $12 \mathrm{~h}$ light-dark cycle, and were acclimated to the environment for 3 weeks before the experiment. A549 cells $\left(3 \times 10^{6}\right.$ cells $/ 10 \%$ FBS $)$ mixed with Matrigel (BD Biosciences, Bedford, MA, USA) in a 1:1 ratio, were subcutaneously (SC) injected into both flanks of each mouse. The A549 cells-derived tumor volume was measured three times a week using a caliper (Mitutoyo, Gyeonggi, Korea), and calculated as $0.5 \times\left(\right.$ length $\times$ width $\left.{ }^{2}\right)\left(\mathrm{mm}^{3}\right)$. The body weight was also measured at the same time as the tumor size measurement. Once the tumor size reached $100 \mathrm{~mm}^{3}$, vehicle $(0.5 \%$ DMSO in corn oil; $\mathrm{n}=7$ ), CDDP (7 mg/kg; $\mathrm{n}=7$ ) and GA (50 mg/ $\mathrm{kg} ; \mathrm{n}=7$ ) dissolved in $0.5 \%$ DMSO and corn oil (Sigma-Aldrich) were administered by intraperitoneal (IP) injection at $150 \mu \mathrm{L}$ for 4 weeks (three times a week for vehicle (0.5\% DMSO in corn oil) and GA, and once a week for CDDP). The mice were sacrificed after 4 weeks, and the tumors were subsequently harvested from the vehicle $(0.5 \% \mathrm{DMSO}$ in corn oil), GA or CDDP treated mice and fixed in $4 \%$ paraformaldehyde. The fixed tumor mass was dehydrated and embedded in paraffin for histological analysis.

\section{Hematoxylin \& Eosin (H\&E) staining}

Paraffin-embedded xenograft tumors were sliced into $5 \mu \mathrm{m}$ sections using a microtome (Leica RM2145, Leica Microsystems, Nussloch, Germany) and collected on the microscope slides. The tissue sections were deparaffinized in xylene for $10 \mathrm{~min}$, and gradually rehydrated in $100,90,80$, and $70 \%$ ethanol and gently running tap water, each for 5 min. Next, the sections were stained with hematoxylin (Merck Millipore, Burlington, MA, USA) and eosin (Merck Millipore) and washed in gently running tap water for $5 \mathrm{~min}$. The tissue sections were subsequently dehydrated in $70,80,90$ and $100 \%$ ethanol, followed by soaking in xylene for $5 \mathrm{~min}$, and then mounted using a Cytoseal (Invitrogen). The tumor mass structure was imaged using the IX-73 inverted microscope (Olympus).

\section{Immunohistochemistry (IHC)}

Paraffin-embedded xenograft tumors were sliced into $5 \mu \mathrm{m}$ sections using a microtome (Leica Microsystems) and collected on the microscope slides. After deparaffinization (as stated above), antigen retrieval was accomplished by boiling the tumor section slides with $0.01 \mathrm{M}$ citrate buffer ( $\mathrm{pH}$ 6.0) for $20 \mathrm{~min}$ in a microwave, and subsequent cooling at room temperature. The slides were blocked with $5 \%$ BSA plus $10 \%$ goat serum in PBS plus Tween-20 for an hour, followed by treatment with $0.3 \% \mathrm{H}_{2} \mathrm{O}_{2}$ (Sigma-Aldrich) for $30 \mathrm{~min}$. The slides were then incubated overnight at $4^{\circ} \mathrm{C}$ with the following primary antibodies: mouse monoclonal anti-proliferating cell nuclear antigen (PCNA; 1:500; Santa Cruz Biotechnology), rabbit polyclonal anti-cleaved caspase-3 (1:200), and rabbit monoclonal anti-p- 
A

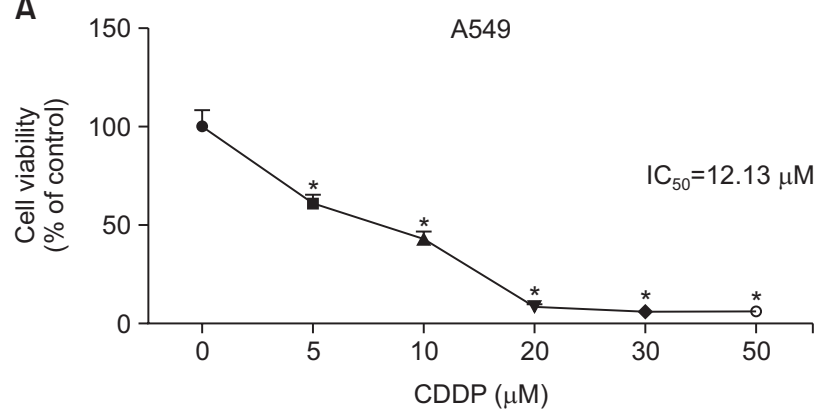

B

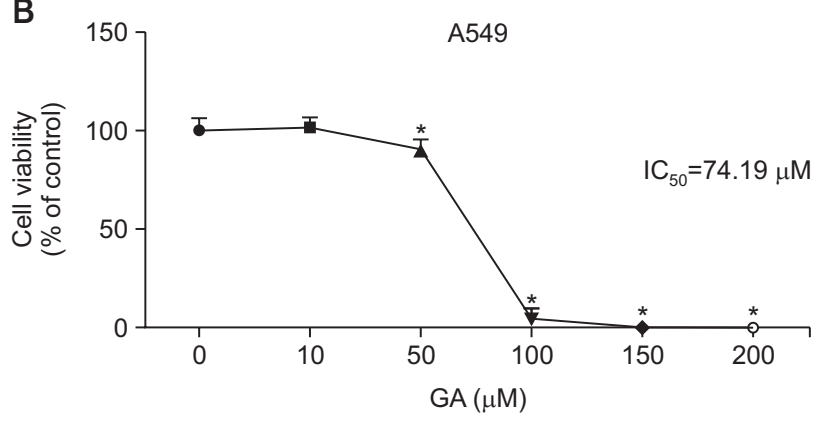

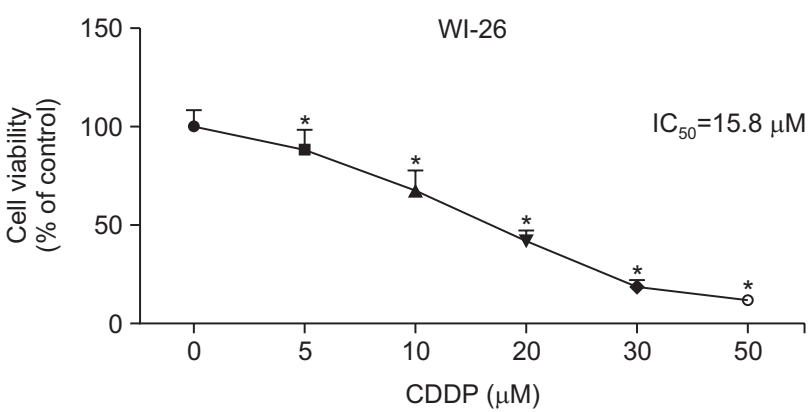

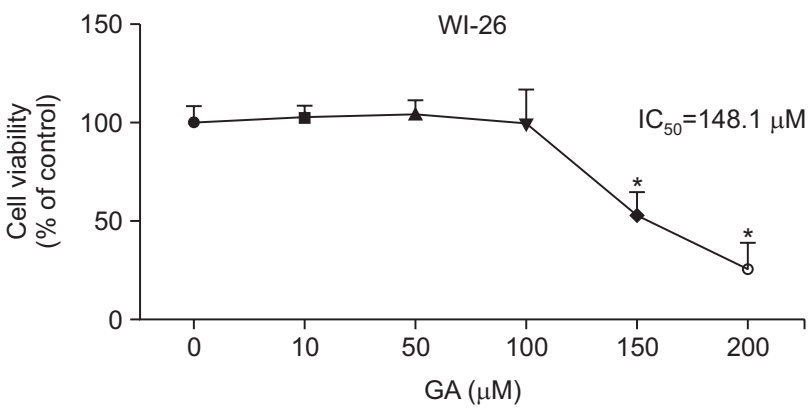

Fig. 2. Effect of GA or CDDP on cell viability of A549 and WI-26 cells. A549 and WI-26 cells were seeded at a density of $5 \times 10^{3}$ cells per well in 96-well plates, and treated with CDDP $(0-50 \mu \mathrm{M})$ and GA $(0-200 \mu \mathrm{M})$ for $48 \mathrm{~h}$. Cell viability was confirmed by WST assay. The data presented the effect of (A) CDDP and (B) GA on cell viability of both cell lines. Data are expressed as means \pm SD from three independent experiments. ${ }^{*} p<0.05$ vs. $0 \mu \mathrm{M}$ (NC; $0.1 \%$ DMSO).

Akt (1:200). Subsequently, the probed slides were incubated with biotinylated mouse or rabbit anti-goat IgG (1:500; Vector Laboratories, Burlingame, CA, USA) secondary antibodies for $30 \mathrm{~min}$ at $37^{\circ} \mathrm{C}$. The sections were then incubated with avidin-biotin complex (ABC; Vector Laboratories) for $30 \mathrm{~min}$ and diaminobenzidine tetrahydrochloride hydrate (DAB; Sigma-Aldrich) for 2 min. Finally, the sections were dehydrated and mounted using a Cytoseal (Invitrogen). The expression of each protein in the tumor mass was observed and visualized using the IX-73 inverted microscope (Olympus).

\section{Data analysis}

All in vitro experiments were conducted at least three times to ensure consistent results, and all data were analyzed with the GraphPad Prism software (GraphPad Software Inc., San Diego, CA, USA). Data were analyzed by one-way analysis of variance followed by a post hoc Dunnett's multiple comparison test, and are expressed as the means \pm standard deviation (SD) or standard error of the mean (SEM). $p$-values $<0.05$ are considered statistically significant versus the negative control.

\section{RESULTS}

\section{Decreased viability of A549 and WI-26 cells following treatment with GA or CDDP}

To evaluate the effect of GA or CDDP on cell viability, the water soluble tetrazolium salt assay was performed using the NSCLC cell line A549 and normal human lung fibroblast cell line WI-26. Both cell lines were exposed to stepwise concentrations of $\operatorname{CDDP}(0-50 \mu \mathrm{M})$ and $\mathrm{GA}(0-200 \mu \mathrm{M})$ for $48 \mathrm{~h}$. The culture medium containing $0.1 \%$ DMSO was applied as the
NC. Although GA and CDDP were dissolved in $0.1 \%$ DMSO and $1.5 \%$ sterile PBS, respectively, no difference was obtained in cell viability when comparing $0.1 \%$ DMSO and $1.5 \%$ sterile PBS (data not shown). Cell viability of both cell lines was inhibited in a dose-dependent manner when exposed to CDDP (Fig. 2A). Exposure to GA significantly decreased cell viability of A549 from 50 to $200 \mu \mathrm{M}$ in a dose-dependent manner. No statistical change was observed at 50 and $100 \mu \mathrm{M} \mathrm{GA}$, but significant inhibition was observed from 150 to $200 \mu \mathrm{M}$ following treatment with GA in WI-26 cells (Fig. 2B). For A549 and $\mathrm{WI}-26$ cells, the inhibitory concentration $50\left(\mathrm{IC}_{50}\right)$ values achieved for CDDP were 12.13 and $15.80 \mu \mathrm{M}$, respectively, and for GA were 74.19 and $148.1 \mu \mathrm{M}$, respectively. Based on these results, $12 \mu \mathrm{M}$ CDDP and $75 \mu \mathrm{M}$ GA were used for subsequent experiments.

\section{Inhibition of the formation of colonies and tumor spheroids by treatment with GA in A549 cells}

The cell survival ability after GA or CDDP exposure was assessed in vitro by the colony formation assay, which is based on the ability of single cells to grow into a colony. Following treatment with $\mathrm{NC}(0.1 \% \mathrm{DMSO})$, CDDP $(12 \mu \mathrm{M})$ and GA $(75 \mu \mathrm{M})$ for 10 days, colonies of A549 single cells were fixed, stained by crystal violet solution, and quantified. A large number of colonies were observed in the NC $(0.1 \%$ DMSO) treated group, but almost all cells were dead, with no colony formation, in the GA and CDDP treatment groups (Fig. 3A). These results indicated that GA or CDDP significantly inhibited the ability of colony formation linked to cell survival.

Tumor spheroid formation assay, in which tumor cells aggregate as 3D structures mimicking the in vivo tumor microenvironment, is a more advanced model than monolayer cul- 
A
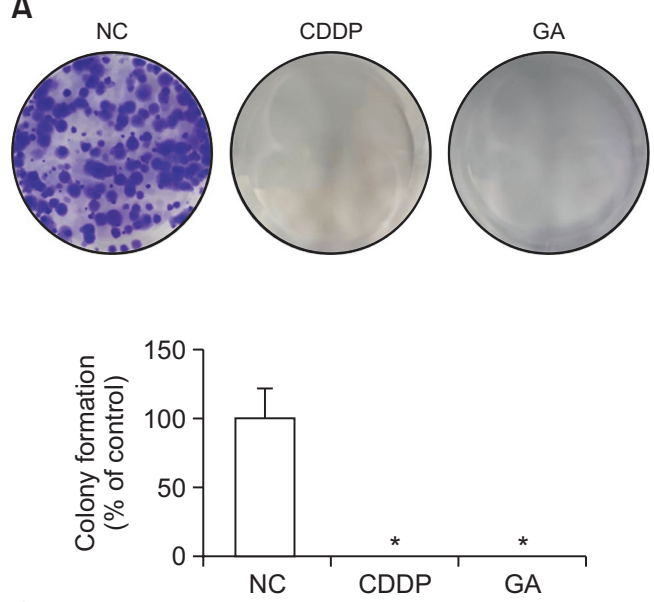

C

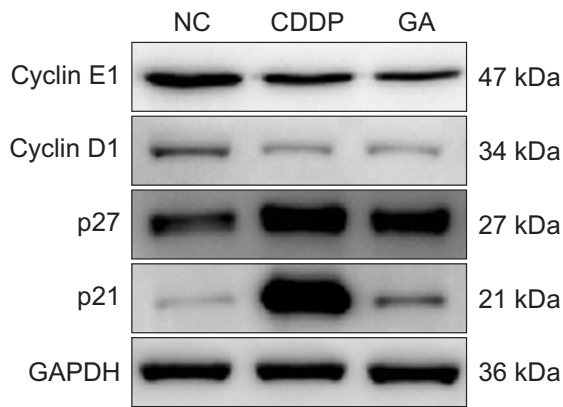

B
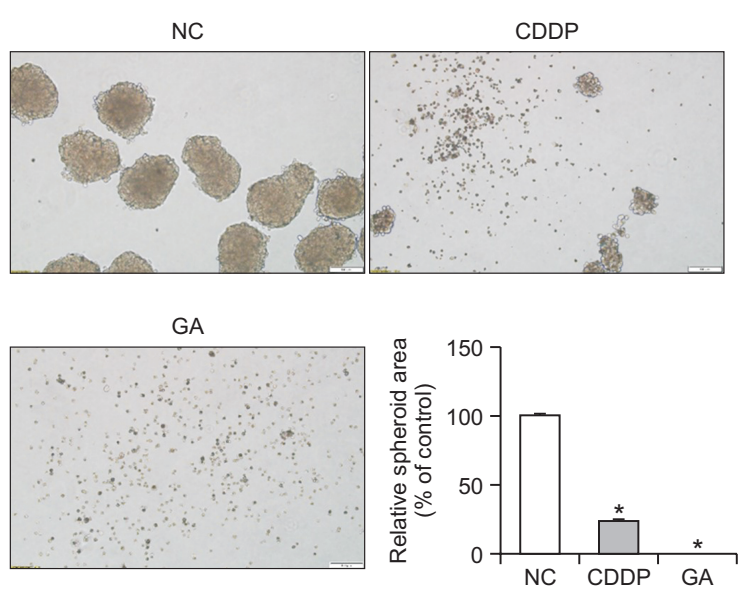

D
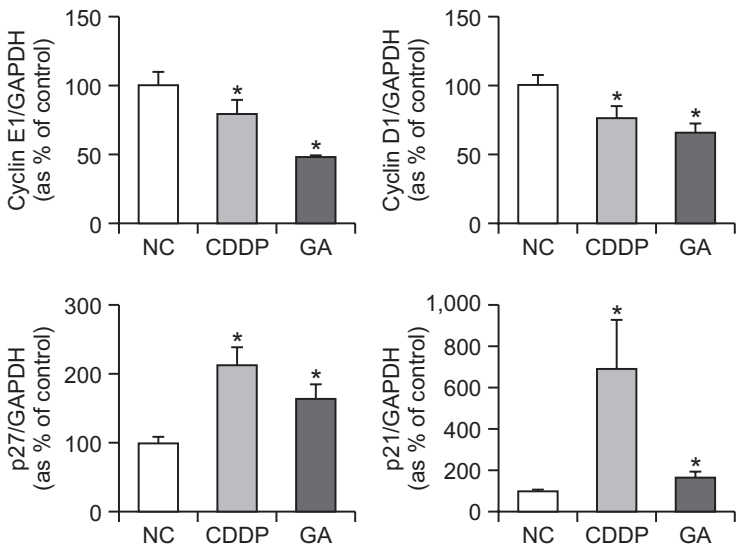

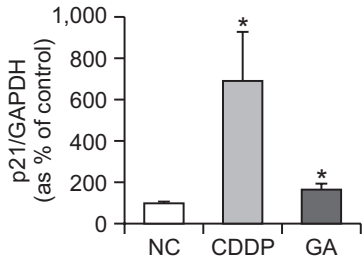

Fig. 3. Effect of GA or CDDP on survival and progression of A549 cells. (A) A549 cells were seeded at a density of 500 cells per well in 6 -well plates, and treated with NC $(0.1 \% \mathrm{DMSO}), \operatorname{CDDP}(12 \mu \mathrm{M})$ and GA $(75 \mu \mathrm{M})$. Colony formation assay was performed to measure the colony forming ability. The number of colonies was quantified using the Image J program. (B) A549 cells were seeded at a density of 500 cells/25 $\mu \mathrm{L} /$ droplet on the lid of petri dish, in appropriate media containing the test compounds, and incubated for 6 days. The size of tumor spheroids generated was determined using the Image $\mathrm{J}$ program. A549 cells were seeded at a density of $6 \times 10^{5}$ cells in cell culture dishes and treated with NC $(0.1 \%$ DMSO), CDDP $(12 \mu \mathrm{M})$ and GA $(75 \mu \mathrm{M})$ for $48 \mathrm{~h}$. (C) The expressions of cell cycle related proteins such as Cyclin D1, Cyclin E1, p21 and p27 were confirmed by Western blot assay. (D) The expression levels of each protein were normalized to GAP$\mathrm{DH}$ and quantified. The representative images were obtained from at least three repeated experiments. Data are expressed as means $\pm \mathrm{SD}$ from three independent experiments. ${ }^{*} p<0.05$ vs. NC $(0.1 \%$ DMSO).

ture of tumor cells. This assay was conducted to evaluate cell proliferation of A549 cells after GA or CDDP treatment in vitro. After culturing with medium containing NC ( $0.1 \%$ DMSO), GA or CDDP for 6 days, the formed tumor spheroids were imaged and quantified. Tumor spheroids were normally formed in the NC $(0.1 \%$ DMSO) group, but were small or not formed in the GA and CDDP treatment groups (Fig. 3B). These results indicated that GA or CDDP hindered tumor spheroid formation of A549 cells. Collectively, these data implied that GA significantly interrupted the cell survival and progression of A549 cells, as effectively as CDDP.

Western blot assay was performed to confirm the effects of GA or CDDP on the expression of cell cycle-related proteins (Fig. 3C). Exposure to GA or CDDP downregulated the expressions of Cyclin D1 and E1 required for progression of the cell cycle, but the expressions of p21 and p27 associated with cell cycle arrest were upregulated by GA or CDDP treatment in A549 cells (Fig. 3D). These results suggested that GA inhibited the cell proliferation by negatively regulating cell cycle progression.

\section{Apoptotic activities of A549 cells by treatment with GA}

To evaluate the apoptotic effects of GA or CDDP on A549 cells, changes in the distribution of early or late apoptotic cells and DNA fragmentation in late apoptosis in A549 cells treated with GA or CDDP were observed through Annexin $V$ assay and TUNEL assay. Flow cytometric analysis of Annexin $V$ assay revealed significantly increased distribution of apoptotic cells, and decreased number of live cells in A549 exposed to GA or CDDP, indicating that treatment with GA or CDDP induced cell apoptosis (Fig. 4A). TUNEL assay showed that exposure to GA or CDDP caused DNA fragmentation, representing late apoptosis. TUNEL-positive cells (green fluorescence) were increased when treated with GA or CDDP. Since most treated cells were non-viable, very few DAPI-stained cells (blue fluorescence) were attached and observed in the GA or CDDP treatment groups. However, based on the percentage of TUNEL-stained cells to normalization of DAPI-stained cells, 
A

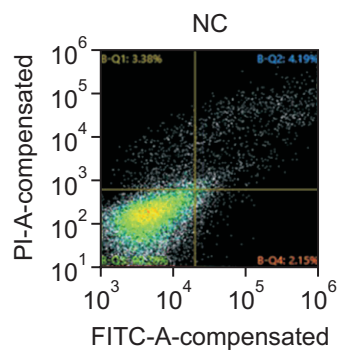

CDDP

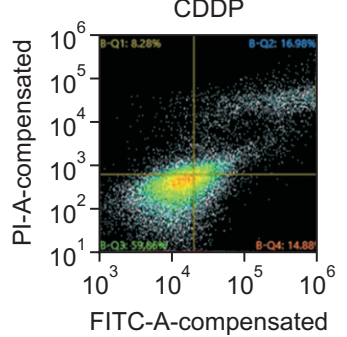

GA

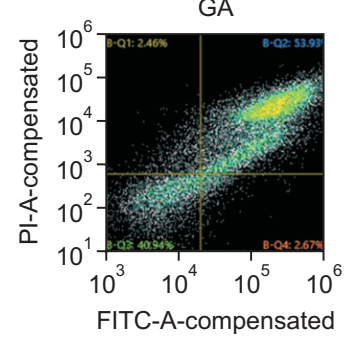

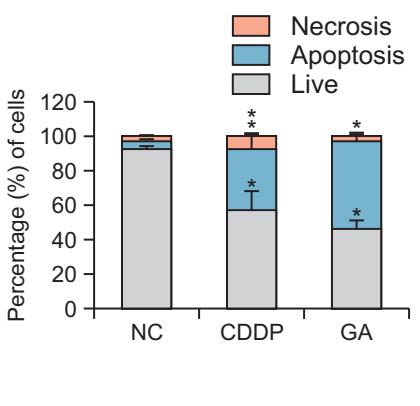

TUNEL
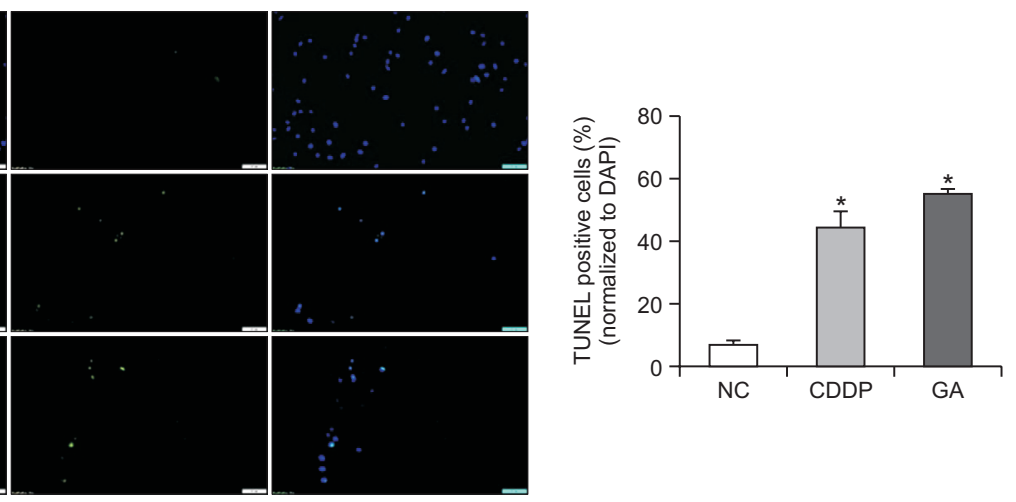
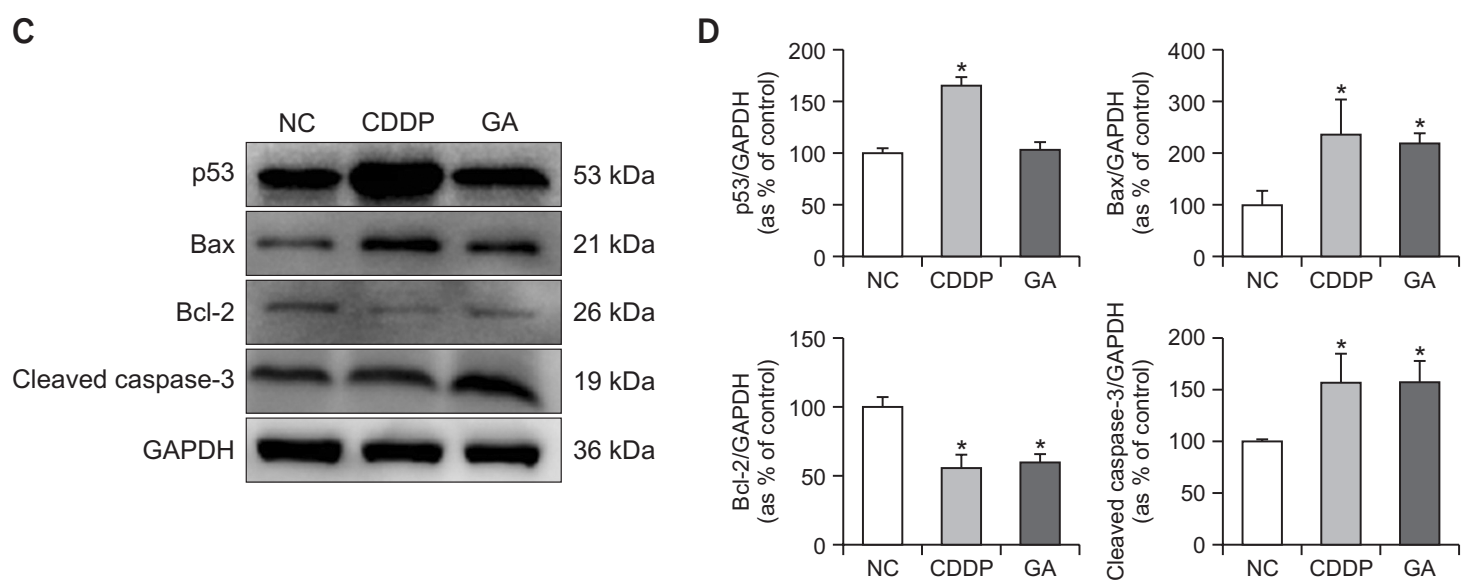

Fig. 4. Effect of GA or CDDP on apoptosis of A549 cells. (A) A549 cells were seeded at a density of $8 \times 10^{4}$ cells per well in cell culture dishes and treated with NC $(0.1 \%$ DMSO), CDDP $(12 \mu \mathrm{M})$ and GA $(75 \mu \mathrm{M})$ for $48 \mathrm{~h}$, and subsequently subjected to Annexin V assay. The cell distribution of apoptosis was analyzed and quantified. (B) A549 cells were seeded at a density of $3 \times 10^{4}$ cells per well in 24 -well plates and treated with NC $(0.1 \%$ DMSO), CDDP $(12 \mu \mathrm{M})$ and GA $(75 \mu \mathrm{M})$ for $48 \mathrm{~h}$; TUNEL assay was conducted and cells were observed under $\times 100$ magnification. DNA fragmentations were stained with TUNEL and all nuclei are stained with DAPI. DNA fragmentations in nuclei were shown in MERGE. The percentage of TUNEL-stained cells for DAPI-stained cells was analyzed using Image $\mathrm{J}$ program. A549 cells were seeded at a density of $6 \times 10^{5}$ cells in cell culture dishes, and treated with NC (0.1\% DMSO), CDDP (12 $\left.\mu \mathrm{M}\right)$ and GA (75 $\left.\mu \mathrm{M}\right)$ for $48 \mathrm{~h}$. (C) The expressions of apoptosis related proteins such as p53, Bax, Bcl-2, and cleaved caspase-3 were determined by Western blot assay. (D) The expression levels of each protein were normalized to GAPDH and quantified. The representative images were obtained from at least three repeated experiments. Data are expressed as means \pm SD from three independent experiments. * $p<0.05$ vs. NC (0.1\% DMSO).

GA or CDDP significantly induced DNA fragmentation in cell nuclei (Fig. 4B). These results indicated that GA induced considerable apoptosis of A549 cells, comparable to CDDP.

The expression of apoptosis related proteins after GA or CDDP treatments was detected by Western blot assay (Fig. 4C). Similar to results achieved in the above experiments, upregulation in the expression of p53 (tumor suppressor protein) was observed only in the CDDP treatment group, but the expression of Bax (pro-apoptotic protein) was significantly upregulated, and the expression of $\mathrm{Bcl}-2$ (anti-apoptotic protein) was downregulated in GA and CDDP treatment groups (Fig. 4D). These results indicated that GA induced cell apoptosis via the intrinsic apoptotic pathway, which occurs through the mitochondria. 
A

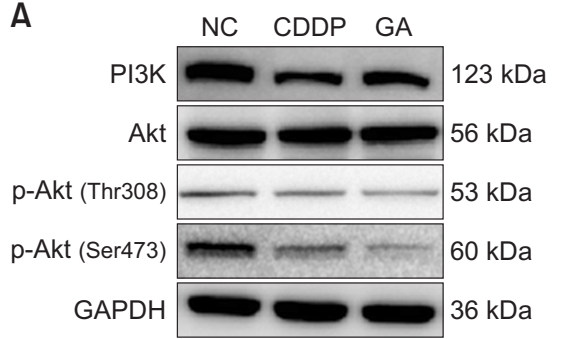

B

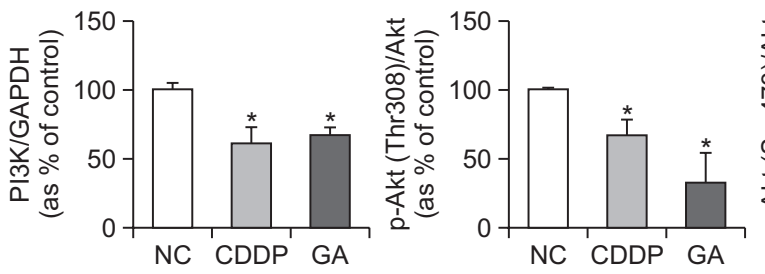

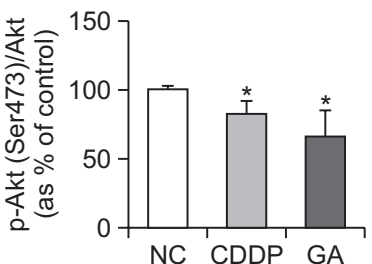

Fig. 5. Effect of GA or CDDP on the expressions of PI3K/Akt pathway related proteins. A549 cells were seeded at a density of $6 \times 10^{5}$ cells in cell culture dishes and treated with NC $(0.1 \%$ DMSO), CDDP $(12 \mu \mathrm{M})$ and GA $(75 \mu \mathrm{M})$ for $48 \mathrm{~h}$. (A) The protein expressions involved in the PI3K/Akt pathway such as PI3K, Akt, and p-Akt (Ser473 and Thr308) were determined by Western blot assay. (B) The expression levels of each protein were normalized to GAPDH for PI3K, and Akt for p-Akt (Ser473 and Thr308), and quantified. Data are expressed as means \pm SD from three independent experiments. ${ }^{*} p<0.05$ vs. NC (0.1\% DMSO).

A

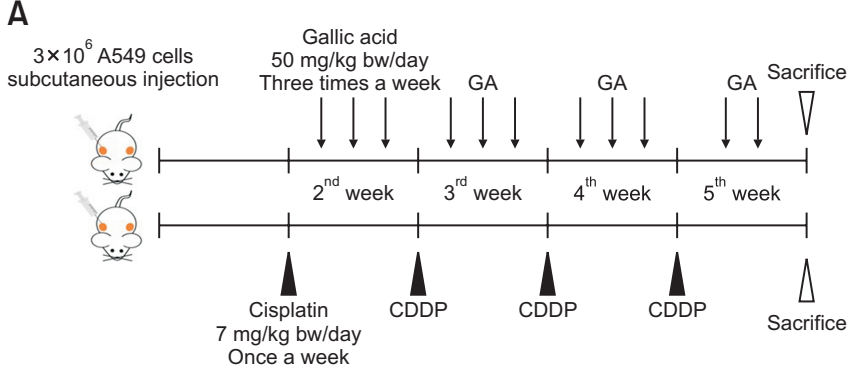

B

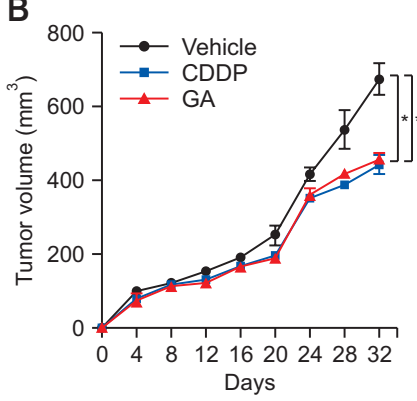

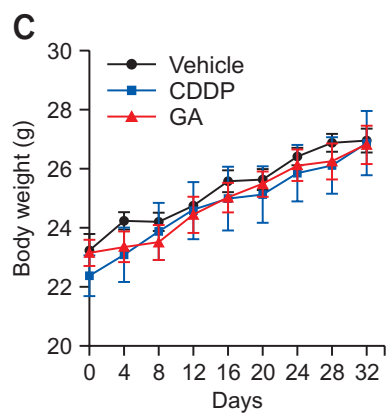

Fig. 6. Effect of GA or CDDP on A549 cells derived tumor xenograft mice model. (A) A549 cells $\left(3 \times 10^{6}\right.$ cells) were implanted SC into both flanks of BALB/c nude male mice. The xenograft mice were IP administered vehicle (0.5\% DMSO in corn oil), CDDP (7 mg/kg), and GA (50 $\mathrm{mg} / \mathrm{kg}$ ) dissolved in $0.5 \%$ DMSO in corn oil. (B) The tumor growth curves in xenograft mice were measured thrice a week. (C) The average body weight of xenograft mice was measured thrice a week. Data are expressed as means \pm SEM. ${ }^{*} p<0.05$ vs. vehicle $(0.5 \%$ DMSO in corn oil).

\section{Alteration of PI3K/Akt pathway related proteins expressions by treatment with GA in A549 cells}

To explore the molecular mechanism of GA-mediated cell cycle arrest and apoptosis compared to CDDP, the expressions of protein associated with PI3K/Akt pathway were examined by Western blot assay (Fig. 5A). Exposure to GA or CDDP significantly decreased the levels of PI3K, and completely inhibited Akt by phosphorylation of Akt at Ser473 and Thr308. No significant difference was observed in the expression of total Akt. These data demonstrated that GA suppressed the PI3K/Akt pathway in A549 cells (Fig. 5B).

\section{Tumor size and body weight in A549 cells derived tumor mouse xenograft model}

To confirm the in vivo anti-tumor effect of GA or CDDP, an A549 cells-derived tumor mouse xenograft model was established using BALB/c nude male mice. On achieving a volume of about $100 \mathrm{~mm}^{3}$ of A549 cells-derived tumors, the xenograft mouse were IP administered vehicle (0.5\% DMSO in corn oil), CDDP (7 mg/kg), and GA (50 mg/kg) dissolved in corn oil for 4 weeks (once a week for CDDP and 3 times a week for GA). The tumor volume and body weight of mice were measured using a caliper and scale, three times a week for 4 weeks (Fig. $6 \mathrm{~A})$. Compared with the vehicle ( $0.5 \% \mathrm{DMSO}$ in corn oil), the increase in tumor volume of xenograft mice was slower in the GA and CDDP treatment groups (Fig. 6B). A steady increase was observed in the body weight of xenograft mice, with no significant difference between groups (Fig. 6C). It was determined that GA treatment by IP injection markedly suppressed the tumor growth in A549 cells-derived tumors of xenograft mice.

\section{Histological analysis of A549 cells derived tumor mass of xenograft mouse model}

The anti-tumor effect of GA was histologically examined in the A549 cells-derived tumor mass of xenograft mice. H\&E staining was performed to observe the structure of xenograft tumors from mice groups treated with GA or CDDP. The tumor mass was characterized by disordered arrangement and nestlike distribution. As shown in Fig. 7, Most cells in the tumor mass of the vehicle ( $0.5 \%$ DMSO in corn oil) were arranged with complete and atypical structures. In the GA and CDDP treatment groups, there were incomplete cell membranes and low tumor density, as compared to vehicle $(0.5 \%$ DMSO in corn oil). IHC was performed to confirm the expressions of PCNA, cleaved caspase-3 and p-Akt in the tumor mass. It was determined that administration of GA or CDDP downregulated the expressions of PCNA and p-Akt, and upregulated the expression of cleaved caspase-3, as compared to the vehicle (0.5\% DMSO in corn oil) (Fig. 7). These findings indicated that IP injection of GA inhibited the tumor growth, which was consistent with in vitro results. 


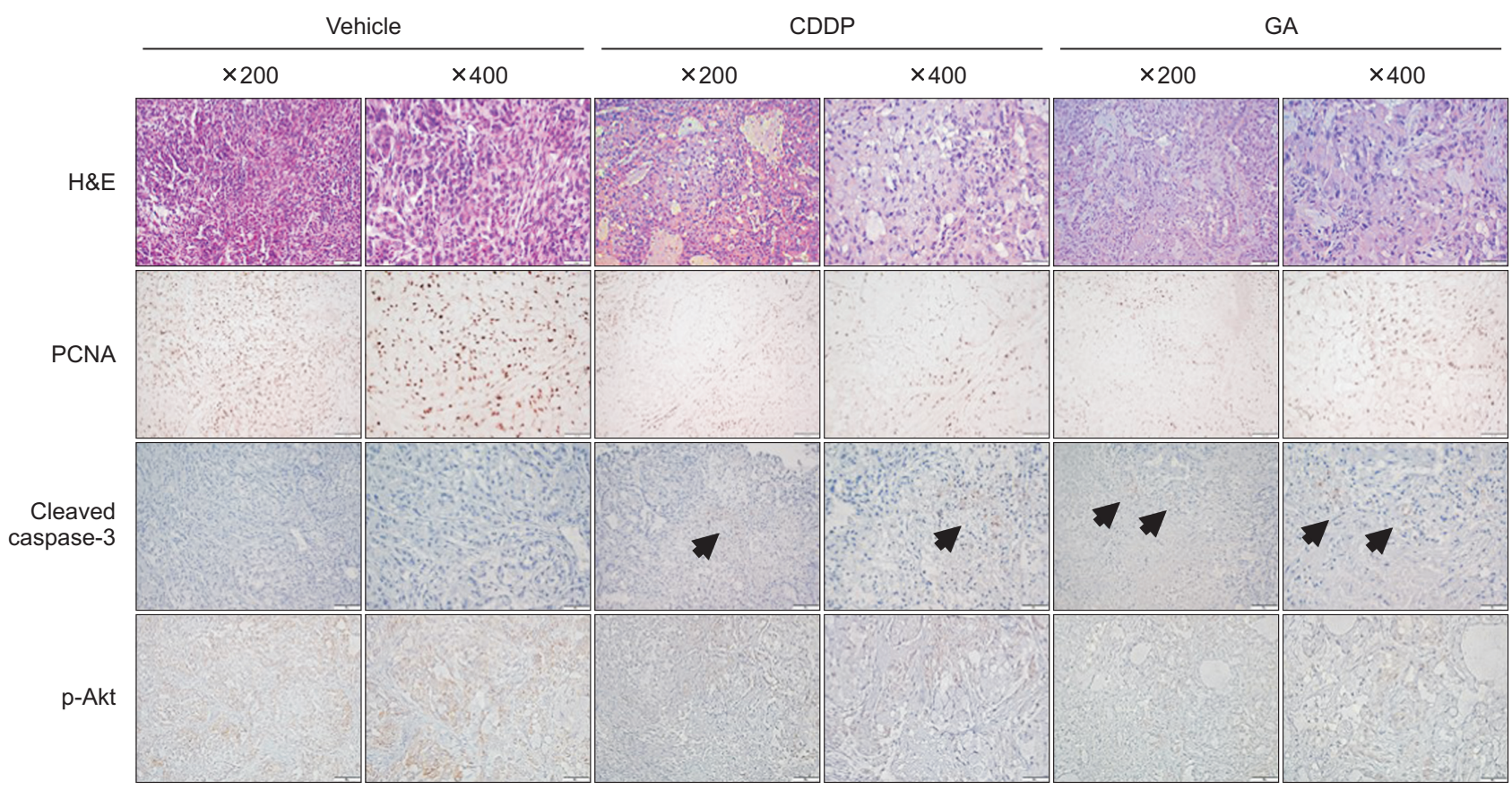

Fig. 7. Effect of GA or CDDP on A549 cells-derived tumor mass of xenograft mice model. A549 cells-derived tumor masses treated with CDDP (7 mg/kg) or GA (50 mg/kg) were stained with H\&E for identifying tumor structure, and with IHC for detecting the expression of PCNA, cleaved caspase-3 (black arrows) and p-Akt. Stained sections were observed at $\times 200$ and $\times 400$ magnification The representative images were obtained from at least three repeated experiments.

\section{DISCUSSION}

GA, as a naturally occurring polyphenol compound, especially exerts its anti-cancer effects by acting on the molecular mechanisms of cell cycle, apoptotic processes, angiogenesis, invasion and metastasis (Verma et al., 2013). An assessment of the no-observed-adverse-effect level of GA in mice revealed that an acute dose of $5,000 \mathrm{mg} / \mathrm{kg}$ was non-toxic, and there was only a slight but non-significant change at a subacute dose of $1,000 \mathrm{mg} / \mathrm{kg}$ (Rajalakshmi et al., 2001). However, the toxicity information on GA itself is virtually limited. There are several studies confirming the anti-cancer activity of GA in vitro (Inoue et al., 1994; Aborehab and Osama, 2019; Jang et al., 2020), but few available studies assessing its action in vivo. To evaluate the anti-cancer effect of GA, this study used the CDDP as a positive control. Since GA has previously been reported as a potential agent to treat various cancers with low or no side effects (Badhani et al., 2015), this study undertook to elucidate the anti-cancer effect of GA on A549 cells, with regard to the molecular mechanisms associated with the PI3K/ Akt pathway.

GA or CDDP significantly inhibited the viability of A549 cells, a cell line of NSCLC that accounts for $85 \%$ of lung cancer. We found that GA dose-dependently affected the viability of human lung cancer cells. The $\mathrm{IC}_{50}$ value for $\mathrm{GA}$ was $74.15 \mu \mathrm{M}$ in A549 cells. This value differs from these previous studies in some cancer cell lines (Moghtaderi et al., 2018; Aborehab and Osama, 2019; Jang et al., 2020), and the genetic alterations in the cells (Liang et al., 2012). However GA induced apoptosis and showed anti-cancer effect (Ji et al., 2009), similar to the results of our study in A549 lung cancer cells. The concentration of GA $75 \mu \mathrm{M}$ in in vitro of this study induced the decrease of A549 cells, but did not affect the WI-26 cells, a normal human lung fibroblast cell line. But, the concentration of IC 50 of CDPP induced the decrease of A649 and WI-26 cells. These data indicated that exposure to CDDP damaged both normal and cancer cells, whereas the concentration of GA toxic in cancer cells was less harmful to normal cells. It has been reported that GA shows cytotoxicity selectively in cancer cells than in normal cells (Chia et al., 2010). Unlike cancer cells that cannot produce enough of the inhibitors, normal cells can resist GA induced apoptosis by releasing the inhibitor of apoptosis (Isuzugawa et al., 2001). These results suggest GA was efficient on cancer cells at a level similar to that of CDDP and less toxic on normal cells as compared to CDDP.

The effects of GA or CDDP on the colony and tumor spheroid forming abilities of A549 cells were confirmed as a series of cell viability assays. Both results were consistent with the results of cell viability assay; exposure to GA or CDDP considerably inhibited the formation of colonies and tumor spheroids of A549 cells. The colony formation assay reflects cell survival and proliferation against the effectiveness of cytotoxic agents (Franken et al., 2006), whereas the tumor spheroid formation assay assesses cell proliferation, including the ability of cells to grow in all directions by interacting with themselves or their surroundings and generating colony-forming units as 3D tumorsphere aggregates similar to tumors in the in vivo environment (Vinci et al., 2012). Therefore, these findings indicated that GA markedly suppressed cell survival and proliferation, similar to CDDP.

The above results were ultimately related to cell cycle progression. Western blot assay proved that GA or CDDP perturbed the protein expressions of cell cycle related genes such as Cyclin D1, Cyclin E1, p21 and p27. In A549 cells, GA or 
CDDP treatment downregulated the expressions of Cyclin D1 and E1. Cyclin D1 and E1 are responsible for the initial and terminal G1 phase, respectively, and these cyclins play a role in G1/S transition (Gao et al., 2004). Moreover, upregulation in the expressions of p21 and p27, which are potent inhibitors of Cyclin E1, was induced by GA (Deshpande et al., 2005; Liu et al., 2017). Since aberrant cell cycle regulation, such as dysregulation of $\mathrm{G} 1 / \mathrm{S}$ transition is one of the representative mutations in cancer, cell cycle arrest is considered a potential strategy to eliminate cancer cells (Collins et al., 1997; Evan and Vousden, 2001). Jang et al. (2020) revealed that GA induced cell cycle arrest at G2/M phase via up-regulating the expression of p21 and p53 in prostate cancer cells. Therefore, further functional studies related cell cycle are necessary to explain a very faint activation of $\mathrm{p} 21$ and $\mathrm{p} 53$ by GA compared to CDDP.

Induction of apoptosis in A549 cells following GA or CDDP treatment was identified by the Annexin $\mathrm{V}$ assay and TUNEL assay. Results of the Annexin $V$ assay revealed that exposure to GA or CDDP increased the distribution of early apoptotic cells and late apoptotic cells, with a reduction in the number of live A549 cells. Along with the increased distribution of apoptotic cells, the TUNEL assay revealed that treatment with GA or CDDP significantly induced DNA fragmentation of A549 lung cancer cells. In accordance with these findings, the levels of apoptosis related proteins were found to be altered after GA or CDDP exposure in A549 cells; the expressions of Bax and cleaved caspase- 3 were upregulated, whereas Bcl-2 was downregulated. However, only CDDP, and not GA, upregulated the expression of p53. p53 activation can be accomplished independently of changes in protein levels, indicating that accumulation of p53 is not always necessary, or even required, for the employment of p53 downstream responses. In other words, even if no increase in p53 levels is observed, p53 can be activated by a different manner, in example, post-translationally (Bellamy, 1997). The p53 and Bcl-2 family proteins such as Bcl-2, Bcl-xl, Bax and Bad are known as key regulators of apoptosis. In the intrinsic pathway, p53 shifts the balance of $\mathrm{Bcl}-2$ family proteins which are located in the mitochondria, leading to permeabilization of mitochondria and apoptosis (Hemann and Lowe, 2006; Xu et al., 2006). Increased Bax promotes the release of cytochrome $c$ from mitochondria into the cytosol, subsequently activating caspase- 3 and inducing apoptosis (Katiyar et al., 2005). Thus, it was determined that GA induced the apoptosis of A549 cells through an intrinsic mitochondrial apoptotic pathway. Maurya et al. (2011) showed that GA drives apoptosis through the intrinsic pathway in A549 cells. Our results provide more detailed information in regard to this concern in this study.

It was studied to some extent in the previous studies that GA inhibited the growth of cancer cells by inactivating the PI3K/Akt signaling pathway (Zhao and $\mathrm{Hu}, 2013$ ), which is in line with our results. Also, there are accumulating evidences that the downregulation of phosphorylated Akt plays a critical role in the growth and survival of various cancer cells by inducing apoptosis. It was found that GA affected the cell viability, proliferation, invasion and angiogenesis through the inactivation of PI3K/Akt and Ras/MAPK signaling pathway in human glioma cells (Lu et al., 2010). Moreover, in another study, GA significantly inhibited the proliferation and metastasis, and promoted apoptosis, and these activities may be closely associated with mitochondrial dysfunction and PI3K/
Akt/NF-kB suppression in T24 bladder cancer cells (Zeng et al., 2020). Thereby, at least partially reducing the level of $p$ AKT signaling protein, which was observed in our study, can be a reason for reducing A549 cell proliferation and survival after treatment with GA. The positive control CDDP used in this study is known to inhibit the PI3K/Akt pathway, sensitizing cancer cells (such as ovarian and melanoma cells) to CDDP-based chemotherapy (Sinnberg et al., 2009; Zhang et al., 2009). The PI3K/Akt pathway is involved in a variety of cellular processes, including cell proliferation, differentiation, survival, and metabolism. However, this pathway is overactivated in cancer cells, which is important for cancer development. Therefore, the inhibition of this pathway might be a valid approach for treating various types of various cancers. Numerous studies are underway to develop treatments for cancer, targeting PI3K/Akt pathway related proteins (Fresno Vara et al., 2004). Following GA or CDDP treatments, the expressions of PI3K and p-Akt were downregulated, with the subsequent effect on the downstream expression of p53 (Ihle and Powis, 2010), which, in turn, modulated the expressions of p21 and Bax (Tian et al., 2017). These results suggested that inhibition of the PI3K/Akt pathway by GA caused changes in the expressions of cell cycle progression and survival related proteins, in tandem with that of $p 53$, leading to $\mathrm{G} 1$ phase arrest and apoptosis in A549 cells.

To further explore the therapeutic potential of GA in lung cancer, a mouse xenograft tumor model was constructed. In agreement with in vitro studies, GA administration $(50 \mathrm{mg} /$ $\mathrm{kg}$ ) for 4 weeks exhibited significant anti-tumor efficacy in the A549 cells-derived tumor mouse xenograft model. Irregular tumor tissue structures and damage to the tumor cell nuclei accompanied with distorted tumor cell membranes were observed in the tumor mass. Moreover, it was revealed that GA inhibited the growth of A549 cells via regulation of p-Akt in vivo, thereby providing experimental data in support of the

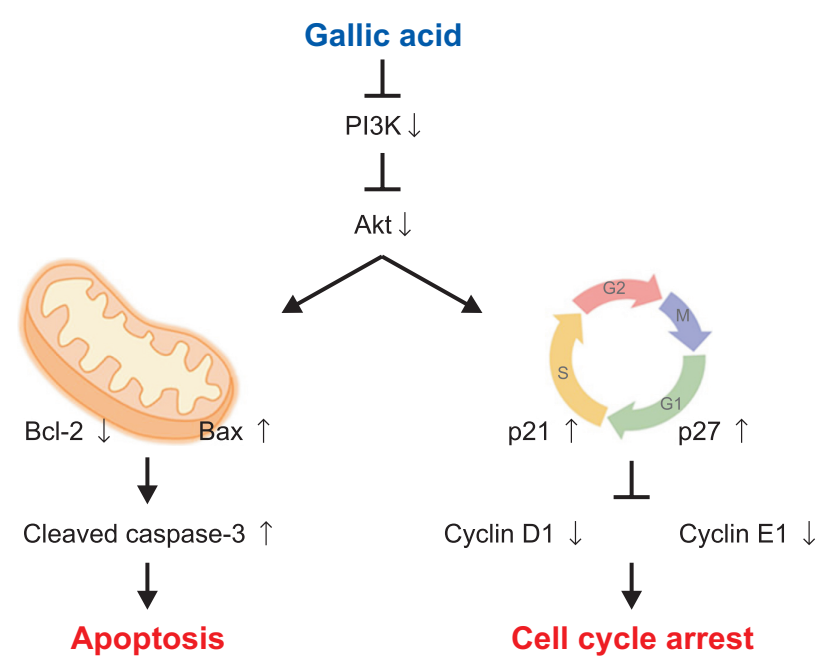

Fig. 8. The anti-cancer effects of GA on A549 cells via PI3K/Akt pathway. GA inhibits PI3K/Akt pathway, and subsequently alters the expressions of Bax and $\mathrm{Bcl}-2$. Increased Bax activates cleaved caspase-3, which induces apoptosis. GA also alters the expressions of p21 and p27 by regulating PI3K/Akt pathway, resulting in downregulation of Cyclin D1 and E1, which subsequently lead to cell cycle arrest. 
clinical application of GA in the treatment of lung cancer.

In conclusion, the findings of the present study determined that GA, a common dietary phenolic compound present in many plant-derived foods, exerted its anti-cancer activities on A549 cells by interrupting cell cycle progression and inducing apoptosis through suppression of the PI3K/Akt pathway (Fig. 8). These results indicated that GA would be an emerging novel and effective therapeutic agent targeting the PI3K/Akt pathway in NSCLC and possibly in other PI3K/Akt-dependent cancers.

\section{CONFLICT OF INTEREST}

The authors do not have any conflicts of interest to declare.

\section{ACKNOWLEDGMENTS}

This work was supported by the Basic Science Research Program (2020R1A2C2006060) and the Global Research and Development Center (GRDC) Program (2017K1A4A3014959) through the National Research Foundation (NRF) of Korea funded by the Ministry of Science and ICT. In addition, this work was also supported by Korea Institute of Planning and Evaluation for Technology in Food, Agriculture, Forestry and Fisheries (IPET) through Agriculture, Food and Rural Affairs Convergence Technologies Program for Educating Creative Global Leader, funded by Ministry of Agriculture, Food and Rural Affairs (MAFRA; grant number: 320005-4).

\section{REFERENCES}

Aborehab, N. M. and Osama, N. (2019) Effect of Gallic acid in potentiating chemotherapeutic effect of Paclitaxel in HeLa cervical cancer cells. Cancer Cell Int. 19, 154

Antognelli, C., Frosini, R., Santolla, M. F., Peirce, M. J. and Talesa, V. N. (2019) Oleuropein-induced apoptosis is mediated by mitochondrial glyoxalase 2 in NSCLC A549 cells: a mechanistic inside and a possible novel nonenzymatic role for an ancient enzyme. Oxid. Med. Cell. Longev. 2019, 8576961.

Badhani, B., Sharma, N. and Kakkar, R. (2015) Gallic acid: a versatile antioxidant with promising therapeutic and industrial applications. RSC Adv. 5, 27540-27557.

Bellamy, C. O. (1997) p53 and apoptosis. Br. Med. Bull. 53, 522-538.

Chang, F., Lee, J. T., Navolanic, P. M., Steelman, L. S., Shelton, J. G., Blalock, W. L., Franklin, R. A. and McCubrey, J. A. (2003) Involvement of PI3K/Akt pathway in cell cycle progression, apoptosis, and neoplastic transformation: a target for cancer chemotherapy. Leukemia 17, 590-603.

Cheng, H., Shcherba, M., Pendurti, G., Liang, Y., Piperdi, B. and Perez-Soler, R. (2014) Targeting the PI3K/AKT/mTOR pathway: potential for lung cancer treatment. Lung Cancer Manag. 3, 67-75.

Chia, Y. C., Rajbanshi, R., Calhoun, C. and Chiu, R. H. (2010) Antineoplastic effects of gallic acid, a major component of Toona sinensis leaf extract, on oral squamous carcinoma cells. Molecules $15,8377-8389$

Choubey, S., Varughese, L. R., Kumar, V. and Beniwal, V. (2015) Medicinal importance of gallic acid and its ester derivatives: a patent review. Pharm. Pat. Anal. 4, 305-315.

Collins, K., Jacks, T. and Pavletich, N. P. (1997) The cell cycle and cancer. Proc. Natl. Acad. Sci. U.S.A. 94, 2776-2778.

Dasari, S. and Tchounwou, P. B. (2014) Cisplatin in cancer therapy: molecular mechanisms of action. Eur. J. Pharmacol. 740, 364-378.

Decatris, M. P., Sundar, S. and O'Byrne, K. J. (2004) Platinum-based chemotherapy in metastatic breast cancer: current status. Cancer Treat. Rev. 30, 53-81.

Deshpande, A., Sicinski, P. and Hinds, P. W. (2005) Cyclins and cdks in development and cancer: a perspective. Oncogene 24, 29092915.

Evan, G. I. and Vousden, K. H. (2001) Proliferation, cell cycle and apoptosis in cancer. Nature 411, 342-348.

Florea, A. M. and Busselberg, D. (2011) Cisplatin as an anti-tumor drug: cellular mechanisms of activity, drug resistance and induced side effects. Cancers (Basel) 3, 1351-1371.

Franken, N. A., Rodermond, H. M., Stap, J., Haveman, J. and van Bree, C. (2006) Clonogenic assay of cells in vitro. Nat. Protoc. 1, 2315-2319.

Fresno Vara, J. A., Casado, E., de Castro, J., Cejas, P., Belda-Iniesta, C. and Gonzalez-Baron, M. (2004) PI3K/Akt signalling pathway and cancer. Cancer Treat. Rev. 30, 193-204.

Gao, N., Flynn, D. C., Zhang, Z., Zhong, X. S., Walker, V., Liu, K. J., Shi, X. and Jiang, B. H. (2004) G1 cell cycle progression and the expression of $\mathrm{G} 1$ cyclins are regulated by PI3K/AKT/mTOR/ p70S6K1 signaling in human ovarian cancer cells. Am. J. Physiol. Cell Physiol. 287, C281-C291.

Gridelli, C., Rossi, A., Carbone, D. P., Guarize, J., Karachaliou, N., Mok, T., Petrella, F., Spaggiari, L. and Rosell, R. (2015) Non-smallcell lung cancer. Nat. Rev. Dis. Primers 1, 15009.

Han, S. W. and Roman, J. (2010) Targeting apoptotic signaling pathways in human lung cancer. Curr. Cancer Drug Targets 10, 566574.

Hemann, M. T. and Lowe, S. W. (2006) The p53-Bcl-2 connection. Cell Death Differ. 13, 1256-1259.

Ihle, N. T. and Powis, G. (2010) Inhibitors of phosphatidylinositol-3-kinase in cancer therapy. Mol. Aspects Med. 31, 135-144.

Inoue, M., Suzuki, R., Koide, T., Sakaguchi, N., Ogihara, Y. and Yabu, Y. (1994) Antioxidant, gallic acid, induces apoptosis in HL-60RG cells. Biochem. Biophys. Res. Commun. 204, 898-904.

Isuzugawa, K., Inoue, M. and Ogihara, Y. (2001) Catalase contents in cells determine sensitivity to the apoptosis inducer gallic acid. Biol. Pharm. Bull. 24, 1022-1026.

Jang, Y. G., Ko, E. B. and Choi, K. C. (2020) Gallic acid, a phenolic acid, hinders the progression of prostate cancer by inhibition of histone deacetylase 1 and 2 expression. J. Nutr. Biochem. 84, 108444.

Ji, B. C., Hsu, W. H., Yang, J. S., Hsia, T. C., Lu, C. C., Chiang, J. H., Yang, J. L., Lin, C. H., Lin, J. J., Suen, L. J., Gibson Wood, W. and Chung, J. G. (2009) Gallic acid induces apoptosis via caspase-3 and mitochondrion-dependent pathways in vitro and suppresses lung xenograft tumor growth in vivo. J. Agric. Food Chem. 57, 7596-7604.

Jones, E. V., Dickman, M. J. and Whitmarsh, A. J. (2007) Regulation of p73-mediated apoptosis by c-Jun N-terminal kinase. Biochem. J. 405, 617-623.

Katiyar, S. K., Roy, A. M. and Baliga, M. S. (2005) Silymarin induces apoptosis primarily through a p53-dependent pathway involving $\mathrm{Bcl}-2 / \mathrm{Bax}$, cytochrome $\mathrm{c}$ release, and caspase activation. Mol. Cancer Ther. 4, 207-216.

Liang, C. Z., Zhang, X., Li, H., Tao, Y. Q., Tao, L. J., Yang, Z. R., Zhou, X. P., Shi, Z. L. and Tao, H. M. (2012) Gallic acid induces the apoptosis of human osteosarcoma cells in vitro and in vivo via the regulation of mitogen-activated protein kinase pathways. Cancer Biother. Radiopharm. 27, 701-710.

Liu, S. L., Liu, Z., Zhang, L. D., Zhu, H. Q., Guo, J. H., Zhao, M., Wu, Y. L., Liu, F. and Gao, F. H. (2017) GSK3beta-dependent cyclin D1 and cyclin E1 degradation is indispensable for NVP-BEZ235 induced G0/G1 arrest in neuroblastoma cells. Cell Cycle 16, 23862395.

Lo, C., Lai, T. Y., Yang, J. H., Yang, J. S., Ma, Y. S., Weng, S. W., Chen, Y. Y., Lin, J. G. and Chung, J. G. (2010) Gallic acid induces apoptosis in A375.S2 human melanoma cells through caspase-dependent and -independent pathways. Int. J. Oncol. 37, 377-385.

Locatelli, C., Filippin-Monteiro, F. B. and Creczynski-Pasa, T. B. (2013) Alkyl esters of gallic acid as anticancer agents: a review. Eur. J. Med. Chem. 60, 233-239.

Loehrer, P. J. and Einhorn, L. H. (1984) Drugs five years later. Cispla- 
tin. Ann. Intern. Med. 100, 704-713.

Lu, Y., Jiang, F., Jiang, H., Wu, K., Zheng, X., Cai, Y., Katakowski, M., Chopp, M. and To, S. S. (2010) Gallic acid suppresses cell viability, proliferation, invasion and angiogenesis in human glioma cells. Eur. J. Pharmacol. 641, 102-107.

Markman, M., Rothman, R., Hakes, T., Reichman, B., Hoskins, W. Rubin, S., Jones, W., Almadrones, L. and Lewis, J. L., Jr. (1991) Second-line platinum therapy in patients with ovarian cancer previously treated with cisplatin. J. Clin. Oncol. 9, 389-393.

Maurya, D. K., Nandakumar, N. and Devasagayam, T. P. (2011) Anticancer property of gallic acid in A549, a human lung adenocarcinoma cell line, and possible mechanisms. J. Clin. Biochem. Nutr. 48, 85-90.

Moghtaderi, H., Sepehri, H., Delphi, L. and Attari, F. (2018) Gallic acid and curcumin induce cytotoxicity and apoptosis in human breast cancer cell MDA-MB-231. Bioimpacts 8, 185-194.

Mou, H., Zheng, Y., Zhao, P., Bao, H., Fang, W. and Xu, N. (2011) Celastrol induces apoptosis in non-small-cell lung cancer A549 cells through activation of mitochondria- and Fas/FasL-mediated pathways. Toxicol. In Vitro 25, 1027-1032.

Pignon, J. P., Tribodet, H., Scagliotti, G. V., Douillard, J. Y., Shepherd, F. A., Stephens, R. J., Dunant, A., Torri, V., Rosell, R., Seymour, L., Spiro, S. G., Rolland, E., Fossati, R., Aubert, D., Ding, K., Waller, D. and Le Chevalier, T.; LACE Collaborative Group (2008) Lung adjuvant cisplatin evaluation: a pooled analysis by the LACE Collaborative Group. J. Clin. Oncol. 26, 3552-3559.

Rajalakshmi, K., Devaraj, H. and Niranjali Devaraj, S. (2001) Assessment of the no-observed-adverse-effect level (NOAEL) of gallic acid in mice. Food Chem. Toxicol. 39, 919-922.

Siegel, R. L., Miller, K. D. and Jemal, A. (2019) Cancer statistics, 2019. CA Cancer J. Clin. 69, 7-34.

Sinnberg, T., Lasithiotakis, K., Niessner, H., Schittek, B., Flaherty, K. T., Kulms, D., Maczey, E., Campos, M., Gogel, J., Garbe, C. and Meier, F. (2009) Inhibition of PI3K-AKT-mTOR signaling sensitizes melanoma cells to cisplatin and temozolomide. J. Invest. Dermatol. 129, 1500-1515.

Sourani, Z. M., Pourgheysari, B. P., Beshkar, P. M., Shirzad, H. P. and Shirzad, M. M. (2016) Gallic acid inhibits proliferation and induces apoptosis in Iymphoblastic leukemia cell line (C121). Iran. J. Med. Sci. 41, 525-530.

Tian, X., Huang, B., Zhang, X. P., Lu, M., Liu, F., Onuchic, J. N. and Wang, W. (2017) Modeling the response of a tumor-suppressive network to mitogenic and oncogenic signals. Proc. Natl. Acad. Sci. U.S.A. 114, 5337-5342.

Verma, S., Singh, A. and Mishra, A. (2013) Gallic acid: molecular rival of cancer. Environ. Toxicol. Pharmacol. 35, 473-485.

Vinci, M., Gowan, S., Boxall, F., Patterson, L., Zimmermann, M.,
Court, W., Lomas, C., Mendiola, M., Hardisson, D. and Eccles, S. A. (2012) Advances in establishment and analysis of three-dimensional tumor spheroid-based functional assays for target validation and drug evaluation. BMC Biol. 10, 29.

Wang, K., Zhu, X., Zhang, K., Zhu, L. and Zhou, F. (2014) Investigation of gallic acid induced anticancer effect in human breast carcinoma MCF-7 cells. J. Biochem. Mol. Toxicol. 28, 387-393.

Wang, R., Ma, L., Weng, D., Yao, J., Liu, X. and Jin, F. (2016) Gallic acid induces apoptosis and enhances the anticancer effects of cisplatin in human small cell lung cancer $\mathrm{H} 446$ cell line via the ROS-dependent mitochondrial apoptotic pathway. Oncol. Rep. 35, 3075-3083.

Wang, X., Martindale, J. L. and Holbrook, N. J. (2000) Requirement for ERK activation in cisplatin-induced apoptosis. J. Biol. Chem. 275, 39435-39443.

Xu, J., Ji, L. D. and Xu, L. H. (2006) Lead-induced apoptosis in PC 12 cells: involvement of $\mathrm{p} 53, \mathrm{Bcl}-2$ family and caspase-3. Toxicol. Lett. 166, 160-167.

You, B. R., Kim, S. Z., Kim, S. H. and Park, W. H. (2011) Gallic acidinduced lung cancer cell death is accompanied by ROS increase and glutathione depletion. Mol. Cell. Biochem. 357, 295-303.

Yousef, M. I., Saad, A. A. and El-Shennawy, L. K. (2009) Protective effect of grape seed proanthocyanidin extract against oxidative stress induced by cisplatin in rats. Food Chem. Toxicol. 47, 11761183.

Yu, J. S. and Cui, W. (2016) Proliferation, survival and metabolism: the role of PI3K/AKT/mTOR signalling in pluripotency and cell fate determination. Development 143, 3050-3060.

Zappa, C. and Mousa, S. A. (2016) Non-small cell lung cancer: current treatment and future advances. Transl. Lung Cancer Res. 5, 288-300.

Zeng, M., Su, Y., Li, K., Jin, D., Li, Q., Li, Y. and Zhou, B. (2020) Gallic acid inhibits bladder cancer T24 cell progression through mitochondrial dysfunction and PI3K/Akt/NF-KB signaling suppression. Front. Pharmacol. 11, 1222.

Zhang, H. Y., Zhang, P. N. and Sun, H. (2009) Aberration of the PI3K/ AKT/mTOR signaling in epithelial ovarian cancer and its implication in cisplatin-based chemotherapy. Eur. J. Obstet. Gynecol. Reprod. Biol. 146, 81-86

Zhao, B. and Hu, M. (2013) Gallic acid reduces cell viability, proliferation, invasion and angiogenesis in human cervical cancer cells. Oncol. Lett. 6, 1749-1755.

Zhou, Y. D., Hou, J. G., Yang, G., Jiang, S., Chen, C., Wang, Z., Liu, Y. Y., Ren, S. and Li, W. (2019) Icariin ameliorates cisplatin-induced cytotoxicity in human embryonic kidney 293 cells by suppressing ROS-mediated PI3K/Akt pathway. Biomed. Pharmacother. 109, 2309-2317. 